\title{
Microgeographical population structure and adaptation in Atlantic cod Gadus morhua: spatio-temporal insights from gene-associated DNA markers
}

\author{
Nina Aagaard Poulsen ${ }^{1,4}$, Jakob Hemmer-Hansen ${ }^{2, *}$, Volker Loeschcke1, \\ Gary Robert Carvalho ${ }^{3}$, Einar Eg Nielsen ${ }^{2}$ \\ ${ }^{1}$ Aarhus University, Department of Biological Sciences, 8000 Aarhus C, Denmark \\ ${ }^{2}$ Technical University of Denmark, National Institute of Aquatic Resources, 8600 Silkeborg, Denmark \\ ${ }^{3}$ Molecular Ecology and Fisheries Genetics Laboratory, School of Biological Sciences, Environment Centre Wales, \\ Bangor University, Bangor, Gwynedd LL57 2UW, UK \\ ${ }^{4}$ Present address: Aarhus University, Faculty of Agricultural Sciences, Department of Food Science, 8830 Tjele, Denmark
}

\begin{abstract}
Recent technical advances have stimulated studies on spatial scales of adaptive genetic variation in marine fishes. However, very few studies have combined spatial and temporal sampling to investigate adaptive genetic structuring at local and microgeographical scales, i.e. scales at which neutral genetic markers have typically revealed very limited levels of population structure. In the present study we analyzed 92 gene-associated single-nucleotide polymorphism (SNP) markers in Atlantic cod Gadus morhua from several sampling sites within the North Sea and adjacent areas. To test for temporal stability, we included long- and short-term (i.e. from 24 to 38 and from 8 to 11 yr, respectively) temporally replicated samples from a subset of populations. As expected, we found very low levels of neutral genetic population structure $\left(F_{\mathrm{ST}}=0.003\right)$. Three specific loci, however, showed highly elevated levels of genetic differentiation. Interestingly, these loci were identical to loci previously found to display signals of adaptive evolution on larger spatial scales. Analysis of historical samples revealed long-term temporally stable patterns of both neutral and adaptive divergence between some populations, indicating long-term temporal adaptive stability driven by strong local selection. In an environmentally dynamic area, on the other hand, patterns of genetic structuring were more variable. Overall, our results not only suggest separation of populations under both evolutionary and ecological paradigms, but also illustrate the usefulness of the spatio-temporal approach for making inferences about the dynamics and geographical distribution of adaptive genetic variation in natural populations.
\end{abstract}

KEY WORDS: Atlantic cod · Adaptive genetic variation · Single nucleotide polymorphism · SNPs · Local selection

Resale or republication not permitted without written consent of the publisher

\section{INTRODUCTION}

Divergent selection resulting from genetic and environmental interactions can potentially result in locally adapted populations, depending on the relative importance of other evolutionary forces (Slatkin 1973, 1987, Kawecki \& Ebert 2004). For instance, to override the homogenizing effects of gene flow in high gene flow species, local selection would be expected to be strong (Hendry et al. 2001, Lenormand 2002). In most nonmodel organisms, inferences of local selection based on population genetic data have been based on the application of genetic markers linked to the polymorphisms under selection. Thus, observed patterns reflect genetic hitchhiking of neutral sites with the true targets of selection (Lewontin \& Krakauer 1973, Smith \& Haigh 
1974, Barton 2000). One classical way of identifying sites that are directly or indirectly subject to selection is to search for loci displaying relatively high levels of population divergence. The identification of such outlier loci is central to approaches based on genome scans (Luikart et al. 2003, Storz 2005), approaches that have recently been facilitated in non-model species by the advent of high through-put technologies for polymorphism discovery and genotyping (Garvin et al. 2010, Thomson et al. 2010). Marine fishes are no exception to this. Here, an increasing number of studies has recently demonstrated signatures of adaptive variation in local demes of several species (Schulte 2001, HemmerHansen et al. 2007, Larsen et al. 2007, Moen et al. 2008, Nielsen et al. 2009a, Bradbury et al. 2010). These studies have challenged the general perception of marine organisms as genetically homogeneous entities. Thus, even though marine fishes are typically characterized by high levels of gene flow and low levels of differentiation at neutral loci (Ward et al. 1994, Waples 1998), strong signatures of local adaptation indicate that it is indeed possible for the effects of selection to override the homogenizing effects of gene flow. Accordingly, low levels of genetic drift due to large effective population sizes (e.g. Poulsen et al. 2006, Therkildsen et al. 2010) and diverse environmental conditions throughout the distributional areas of many species seem to promote adaptive population divergence at spatial scales not previously recognized. Such apparent adaptive diversity could have profound consequences for population persistence. Currently, many marine fish populations are in a depleted state, and, in view of the potential negative effects of global warming and fisheries-induced evolution (Jørgensen et al. 2007), more studies are focusing on the need to assess adaptive divergence at temporal and spatial scales to predict individual population trajectories (Nielsen et al. 2009b).

With regard to Atlantic cod Gadus morhua, intensive efforts have been made to apply neutral DNA markers to examine population structure at various spatial scales ranging from differentiation among major spawning areas (Bentzen et al. 1996, Nielsen et al. 2001, O'Leary et al. 2007) to investigating fine-scaled population structure over short geographical distances (e.g. Ruzzante et al. 1996, Hutchinson et al. 2001, Nielsen et al. 2003). Several studies have found differences in important life-history traits between cod populations, even at local geographical scales (Brander 2005, Marcil et al. 2006, Hutchings et al. 2007, Olsen et al. 2008, Grabowski et al. 2009, Harrald et al. 2010).

Evidence for adaptive population divergence in Atlantic cod has also accumulated from recent studies applying genetic markers to natural populations. For instance, Moen et al. (2008), in comparisons of northeast Arctic and Norwegian coastal cod, identified sev- eral gene-associated single-nucleotide polymorphisms (SNPs) as candidate loci under selection. Nielsen et al. (2009a) found strong signals of directional selection in Atlantic cod associated with populations at both global and local geographical scales. In addition, they found genetic variation in candidate genes for stress response, reproduction and light perception to be associated with local variation in salinity and temperature conditions. Likewise, Bradbury et al. (2010) found evidence of parallel temperature-associated adaptive clines in the eastern and western North Atlantic for $2.4 \%$ of the gene-associated polymorphisms examined. Such results suggest strongly that local adaptations are indeed prevalent in Atlantic cod. However, although evidence for adaptive divergence in Atlantic cod is growing, relatively few studies have investigated patterns of adaptive variation at microgeographical scales. In one recent study, Nielsen et al. (2009c) found that local patterns of genetic structuring were highly influenced by a few allegedly neutral microsatellite loci, suggesting hitchhiking selection at linked gene loci. These results were taken to indicate either fluctuating selection at different life stages or truly adaptive differentiation among recently diverged populations not yet in migration-drift equilibrium. Thus, since microgeographical population structure is at the limit of detection with neutral genetic markers, loci subject to selection could prove highly valuable for separating demographically independent populations (Waples \& Gaggiotti 2006). Genetic variation in life-history traits in areas where neutral markers fail to identify population structuring also suggests that the spatial scale of adaptive evolution is smaller than previously thought, coinciding with the expectation that adaptive divergence occurs on shorter time scales than neutral divergence (Conover et al. 2006, Hutchings et al. 2007). However, to our knowledge, no one has so far performed a temporally replicated geographical investigation of a high number of gene-associated DNA markers to study the spatio-temporal dynamics of local adaptation at microgeographical scales in cod or in other marine fishes.

In the present study, we investigated population structure at local and microgeographical scales in the North Sea, where population structure, as assessed through neutral genetic markers, is low or absent (Hutchinson et al. 2001, Nielsen et al. 2009c). We did so through spatio-temporal sampling and analysis of gene-associated genetic markers. This strategy permitted us to make inferences about the evolutionary dynamics of adaptive population divergence and provided unique information about the relative importance of various evolutionary forces at very fine geographical scales. Moreover, long-term and short-term temporal sampling provided insights into the stability of previously observed regional genetic breaks. 


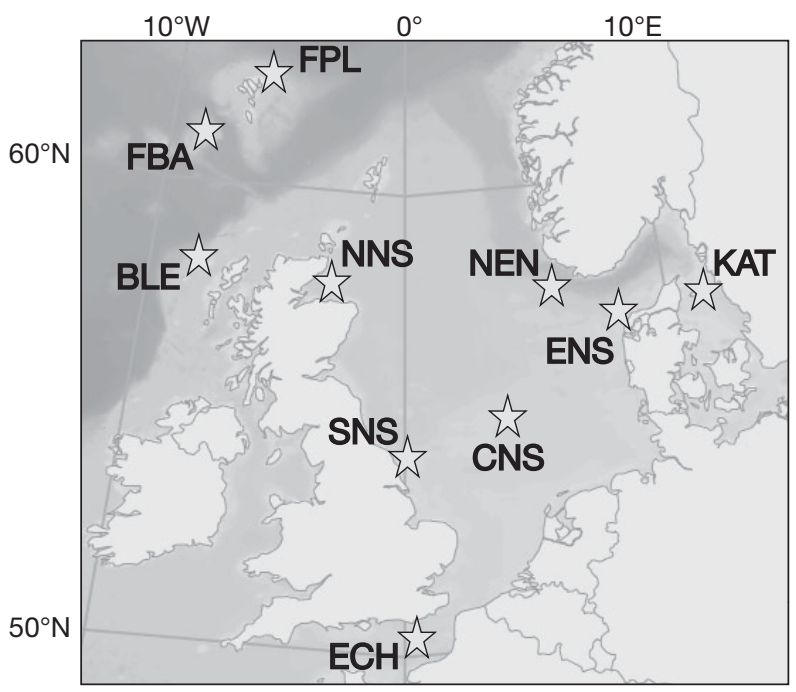

Fig. 1. Gadus morhua sampling locations in the North Sea and adjacent sea areas. BLE: Butt of Lewis; CNS: central North Sea; ECH: English Channel; ENS: eastern North Sea; FBA: Faroe Bank; FPL: Faroe Plateau; KAT: Kattegat; NEN: northeastern North Sea; NNS: northern North Sea; SNS: southern North Sea

\section{MATERIALS AND METHODS}

Sampling locations and molecular analysis. We analyzed relatively homogeneously distributed samples of cod covering most of the North Sea and the adjacent sea areas of Kattegat and around the Faroe Islands (Fig. 1, Table 1). Sampling included 2 shortterm (from 8 to $11 \mathrm{yr}$ ) and 3 longterm (from 24 to $38 \mathrm{yr}$ ) replicates. Although time scales are different, we refer to all these temporal replicates as historical samples. DNA was extracted from contemporary samples of gill tissue, fin clips or blood, whereas DNA from historical samples was extracted from archived otolith collections supplied by Marine Scotland Science (BLE65, NNS65) and the Faroese Fisheries Laboratory (FBA78). DNA from otoliths was extracted using the Proteinase K/chelex method (Estoup et al. 1996), while DNA from tissues was extracted using the E.Z.N.A. Tissue DNA kit (Omega Bio-Tek). In total, 585 individuals were genotyped for 92 SNPs using a MassARRAY system from SEQUENOM, as outlined in Moen et al. (2008). The 92 SNPs included 81 expressed sequence tag (EST)-derived SNPs developed by Moen et al. (2008) and 11 SNPs primarily identified by screening genomic DNA for variation in candidate genes for thermal stress tolerance, growth and reproduction (Nielsen et al. 2009a). Norwegian coastal cod was used as the genetic resource for EST sequencing (Moen et al. 2008), while candidate genes were sequenced in eastern Atlantic and Baltic Sea cod. Most SNPs were located in coding regions (see also Nielsen et al. 2009a). Neutral population structure was examined by excluding all loci previously shown to display signatures of adaptive population differentiation (10 loci; see Nielsen et al. 2009a).

Statistical analysis. Gene diversity and tests for deviations from Hardy-Weinberg equilibrium for each locus in each sample were conducted using the exact test implemented in the software FSTAT (Goudet 1995). Significance of spatio-temporal population differentiation was assessed by permutation tests, and pairwise $F_{\mathrm{ST}} \mathrm{S}$ were estimated using the unbiased estimator $\theta$ (Weir \& Cockerham 1984) in FSTAT. ViSta 5.6.3 (Young 1996) was used for multidimensional scaling (MDS) of pairwise $F_{\mathrm{ST}}$ estimates. Variance components among spatial and temporal samples were estimated using an analysis of molecular variance (AMOVA) implemented in the program Arlequin ver. 3.1 (Excoffier et al. 2005), with significance levels based on 10000 permutations.

To scan for outlier loci under selection we used the Bayesian likelihood method implemented via reversible-jump Markov Chain Monte Carlo in BayeScan 2.01 (Foll \& Gaggiotti 2008). The method allows for

Table 1. Gadus morhua. Details of sampling program. Peak spawning month according to Brander (2005)

\begin{tabular}{|c|c|c|c|c|}
\hline Locality & Position & $\begin{array}{l}\text { Sampling } \\
\text { year } \\
\text { (abbrev.) }\end{array}$ & $\begin{array}{l}\text { No. of } \\
\text { ind. } \\
\text { sampled }\end{array}$ & $\begin{array}{c}\text { Peak } \\
\text { spawning } \\
\text { month }\end{array}$ \\
\hline Kattegat $^{\mathrm{a}}$ & $57.15^{\circ} \mathrm{N}, 11.35^{\circ} \mathrm{E}$ & 1996 (KAT96) & 40 & Apr \\
\hline Kattegat & $57.15^{\circ} \mathrm{N}, 11.35^{\circ} \mathrm{E}$ & 2007 (KAT07) & 40 & Apr \\
\hline Eastern North Sea & $57.10^{\circ} \mathrm{N}, 08.20^{\circ} \mathrm{E}$ & 1999 (ENS99) & 40 & Apr \\
\hline Eastern North Sea & $56.45^{\circ} \mathrm{N}, 07.30^{\circ} \mathrm{E}$ & 2007 (ENS07) & 40 & Apr \\
\hline Southern North Sea ${ }^{a}$ & $54.29^{\circ} \mathrm{N}, 00.02^{\circ} \mathrm{E}$ & 2006 (SNS) & 40 & Apr \\
\hline English Channel $^{\mathrm{a}}$ & $50.47^{\circ} \mathrm{N}, 0.29^{\circ} \mathrm{E}$ & $2006(\mathrm{ECH})$ & 40 & Feb \\
\hline Central North Sea ${ }^{a}$ & $55.17^{\circ} \mathrm{N}, 03.39^{\circ} \mathrm{E}$ & 1996 (CNS) & 40 & Apr \\
\hline Northeastern North Sea & $57.45^{\circ} \mathrm{N}, 05.30^{\circ} \mathrm{E}$ & 2007 (NEN) & 40 & Apr \\
\hline Northern North Sea & Unknown & 1965 (NNS65) & 33 & Apr \\
\hline Northern North Sea ${ }^{a}$ & $58.00^{\circ} \mathrm{N}, 03.00^{\circ} \mathrm{W}$ & 2003 (NNS03) & 40 & Apr \\
\hline Butt of Lewis & Unknown & 1965 (BLE65) & 40 & Apr \\
\hline Butt of Lewis & $59.58^{\circ} \mathrm{N}, 05.15^{\circ} \mathrm{W}$ & 2003 (BLE03) & 40 & Apr \\
\hline Faroe Plateau $^{\mathrm{a}}$ & $62.53^{\circ} \mathrm{N}, 06.18^{\circ} \mathrm{W}$ & 2002 (FPL) & 40 & Mar \\
\hline Faroe Bank ${ }^{\mathrm{a}}$ & Unknown & 1978 (FBA78) & 32 & Mar \\
\hline Faroe Bank $^{\mathrm{a}}$ & $60.56^{\circ} \mathrm{N}, 08.52^{\circ} \mathrm{W}$ & 2002 (FBA02) & 40 & Mar \\
\hline
\end{tabular}


population-specific $F_{\mathrm{ST}}$ estimates (Beaumont \& Balding 2004, Foll \& Gaggiotti 2008) and should therefore be appropriate for Atlantic cod, which is expected to display non-symmetrical patterns of gene flow among natural populations. BayeScan 2.01 estimates the posterior odds (PO), which is the ratio of the posterior probabilities of 2 models (selection vs. neutral). PO between 32 and $100\left(\log _{10} \mathrm{PO}=1.5-2\right)$ yields 'very strong evidence' of different statistical support for the 2 models and corresponds to a posterior probability between 0.97 and 0.99 , while PO $>100$ is interpreted as 'decisive', corresponding to posterior probabilities between 0.99 and 1. A posterior probability of infinity was assigned a $\log _{10}$ PO of 5 . In order to control the false discovery rate (FDR), a PO threshold was calculated for a corresponding FDR of $5 \%$, with an R function distributed with the program (available from http://cmpg.unibe.ch/software/ bayescan/index.html). We used prior odds of 10:1 for the neutral model, 50 pilot runs with 5000 samplings and an additional burn-in of 50000 . Parameters were obtained through 5000 samplings, with a thinning interval of 50. Convergence was assessed using Geweke convergence diagnostics (see Smith 2007 and references therein), assessed between the first 10 and last $50 \%$ of the chain with the package boa for R (Smith 2007; R Development Core Team 2010). In order to assess consistency of results, we compared results of 2 independent runs for each data set. A run was discarded if the likelihood did not converge. Since the outlier detection method does not work well with loci containing limited information (Beaumont \& Balding 2004, see also documentation for BayeScan available from http:// cmpg.unibe.ch/software/bayescan/index.html), we discarded all loci with a minor allele frequency below $2 \%$ in each run.

Least-squares linear regression was used to assess the relationship between single loci and latitude and longitude. Latitude and longitude were used as geographical proxies to reflect geographical patterns in the data set. Regression analyses were carried out in $\mathrm{R}$ (R Development Core Team 2010).

\section{RESULTS}

\section{Data quality and levels of genetic variation}

Three loci (Gm0545_0279, Gm402_0530 and Gm_snp1) showed significant deviations from Hardy-Weinberg equilibrium after sequential Bonferroni correction for multiple testing (Rice 1989). Disequilibria were observed in different populations, and only one deviation was observed in a historical sample (results not shown). Overall, the level of genetic variation was similar among the 3 long-term historical samples and their contemporary replicates (expected heterozygosity $\left[H_{\mathrm{e}}\right]$ historical $=0.226 ; H_{\mathrm{e}}$ contemporary $=0.225$ ) .

\section{Neutral population structure and temporal stability}

The estimated levels of genetic differentiation for individual loci ranged from -0.0035 to 0.0175 for 82 putative neutral markers. Only 2 of the overall pairwise $F_{\mathrm{ST}}$ estimates were significantly different from zero after Bonferroni corrections. These were between the Kattegat sample from 1996 (KAT96) and both of the contemporary Faroe samples (FBA02 and FPL02). Overall, 25 of the 105 pairwise tests showed p-values below 0.05 , but most of these (22 of 25) were associated with Faroe Bank or Plateau samples and/or Kattegat samples. Low and non-significant levels of genetic differentiation were observed within the North Sea area (see Table A1 (without outliers) in the Appendix).

Pairwise tests for temporal genetic differentiation, including both long-term and short-term samples, demonstrated low and non-significant genetic differentiation $\left(F_{\mathrm{ST}}\right)$ ranging from 0.0008 among northern North Sea samples to 0.0063 among Kattegat samples (Table A1). The MDS plot further illustrates the intrapopulation stability and overall homogeneity among North Sea samples (Fig. 2). AMOVA revealed no significant temporal variance components, while spatial variance (within groups) was significant $(p=0.01158)$ for the long-term comparison, and close to significant $(p=0.05812)$ for the short-term comparison (Table 2).

\section{Outlier detection}

From 3 to $8 \%$ of parameters showed a lack of convergence ( $5 \%$ significance level) in individual runs in BayeScan. However, results were highly consistent with respect to the identification of outliers between 2 independent runs for the same data sets (results not shown).

When including all contemporary samples in BayeScan, we detected 3 loci potentially influenced by directional selection, while none showed evidence of balancing selection. All 3 loci (Hsp90, Gm0738_0160 and Gm1386_0216) had high statistical support as outliers (Fig. 3a). When using only North Sea contemporary samples (excluding Faroe Bank, Faroe Plateau and Kattegat samples), Gm0738_0160 remained a significant outlier (Fig. 3b). Historical and contemporary BayeScan runs, including NNS, BLE and FBA, identified Gm1386_0216 as a highly significant $F_{\mathrm{ST}}$ outlier in both historical and contemporary data sets (Fig. 3c,d). The spatial comparison between eastern North Sea and Kattegat samples at 2 time points (KAT96, ENS99; 

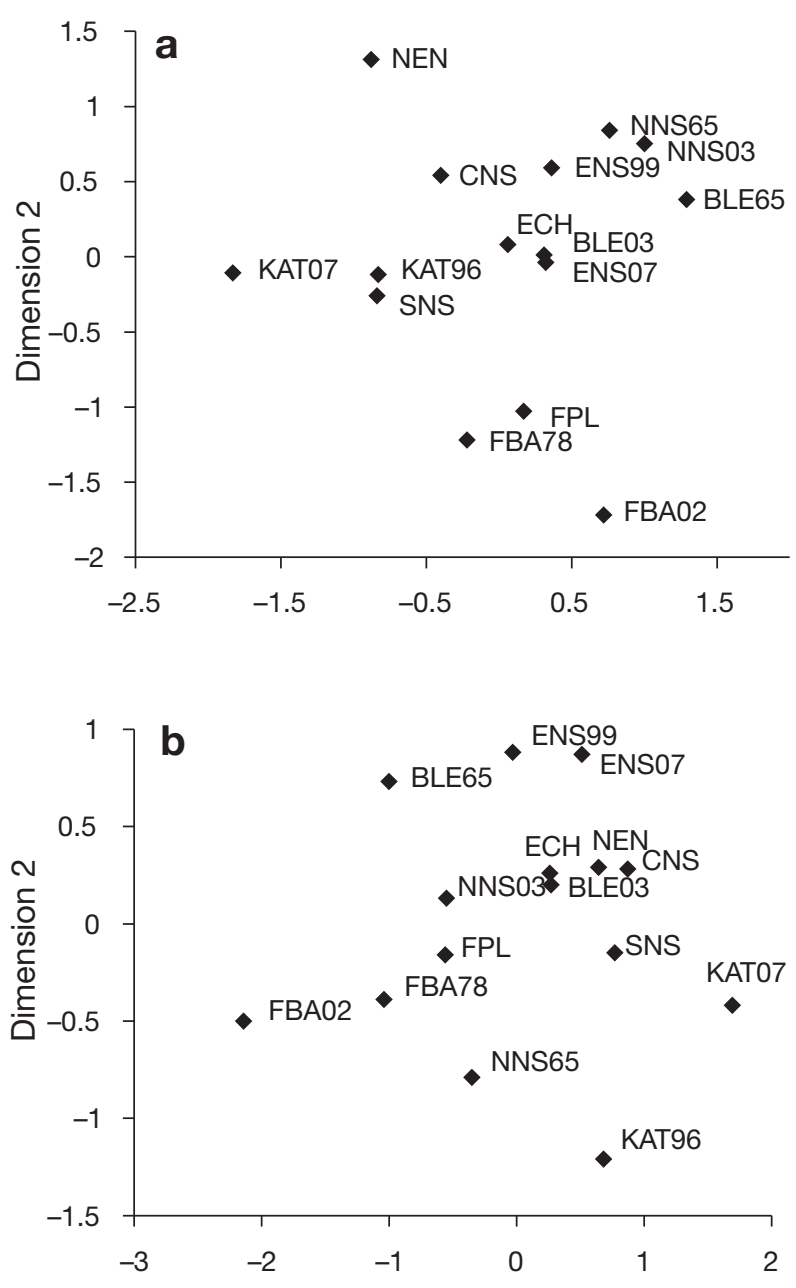

Dimension 1

Fig. 2. Multidimensional scaling (MDS) plots, including (a) all loci and (b) 'neutral' loci genetic differentiation $\left(F_{\mathrm{ST}}\right)$ estimates (Weir \& Cockerham 1984) among spatial and temporal Gadus morhua samples including all populations. Neutral loci $(\mathrm{N}=82)$ : loci not previously shown to be influenced by selection. See Fig. 1 for sampling locations; number following sample name: last 2 digits of year sample was collected
A marked change was evident for Hsp90 allele frequencies in Kattegat samples, whereas in Gm1386_ 0216 an allele frequency change was observed for both Faroe Bank and Kattegat samples (Table 3). Compared to samples from surrounding areas, Gm0738_0160 showed the highest allele frequency change in samples from both the northeastern North Sea (NEN) and the central North Sea (CNS).

\section{Allele frequency clines}

Apart from a significant linear relationship between Hsp90 allele frequencies and longitude $\left(\mathrm{R}^{2}=0.49, \mathrm{p}=\right.$ 0.023), no significant association was found between any of the 3 outlier loci and the latitude or longitude used as geographical proxies (results not shown).

\section{Effects of single loci on patterns of differentiation}

Pairwise $F_{\text {ST }}$ estimates using all 92 loci (allegedly neutral and selected) revealed that 45 out of 105 tests had p-values below 0.05 (Table A2), thus indicating higher levels of genetic structuring than that observed using neutral loci alone (see 'Neutral population structure and temporal stability' above). After Bonferroni correction, 8 of these remained significant but, as observed with the neutral markers, this pattern was driven mainly by Faroe populations, including either FPL02 or FBA02 ( 7 out of 8 significant comparisons). Significant genetic differentiation was, however, also observed between the northeastern North Sea sample (NEN) and the eastern North Sea sample from 2007 (ENS07; Table A2). The MDS plot further revealed the isolated status of the NEN sample. When including all 92 loci in the AMOVA, the temporal variance components were not significantly different from zero, while the spatial components were both statistically significant and higher than estimates based on neutral markers only (Table 2).
KAT07, ENS07) showed no significant outliers when assessed with traditional cut-off points for PO (see 'Materials and methods' and Fig. 3e,f). Both Hsp90 and Gm1386_0216, however, showed increased levels of differentiation. The patterns of structuring for the historical and contemporary comparisons were nonetheless different, as Gm1386_0216 and Hsp90 were found to display relatively high levels of structure in the contemporary and historical comparisons, respectively.
Table 2. Analysis of molecular variance (AMOVA) and its significance among temporal and spatial Gadus morhua samples. Variance among populations within groups (Vb: spatial variance) and variance among groups (Va: temporal variance) are given for analyses involving long-term (Group FBA02, NNS03, BLE03 vs. Group FBA78, NNS65, BLE65), and short-term (Group ENS07, KAT07 vs. Group ENS99, KAT96) temporal data. 92 loci refers to the complete data set; 82 loci refers to the data set without outliers

\begin{tabular}{|lcccc|}
\hline Analysis & $\mathrm{Vb}$ & $\mathrm{p}$ & $\mathrm{Va}$ & $\mathrm{p}$ \\
\hline Long-term samples $(\mathrm{N}=92)$ & 0.04007 & 0.03832 & -0.02661 & 1.00000 \\
Long-term samples $(\mathrm{N}=82)$ & 0.03739 & 0.01158 & -0.02288 & 1.00000 \\
Short-term samples $(\mathrm{N}=92)$ & 0.05245 & 0.01099 & -0.01594 & 1.00000 \\
Short-term samples $(\mathrm{N}=82)$ & 0.03842 & 0.05812 & -0.01340 & 1.00000 \\
\hline
\end{tabular}



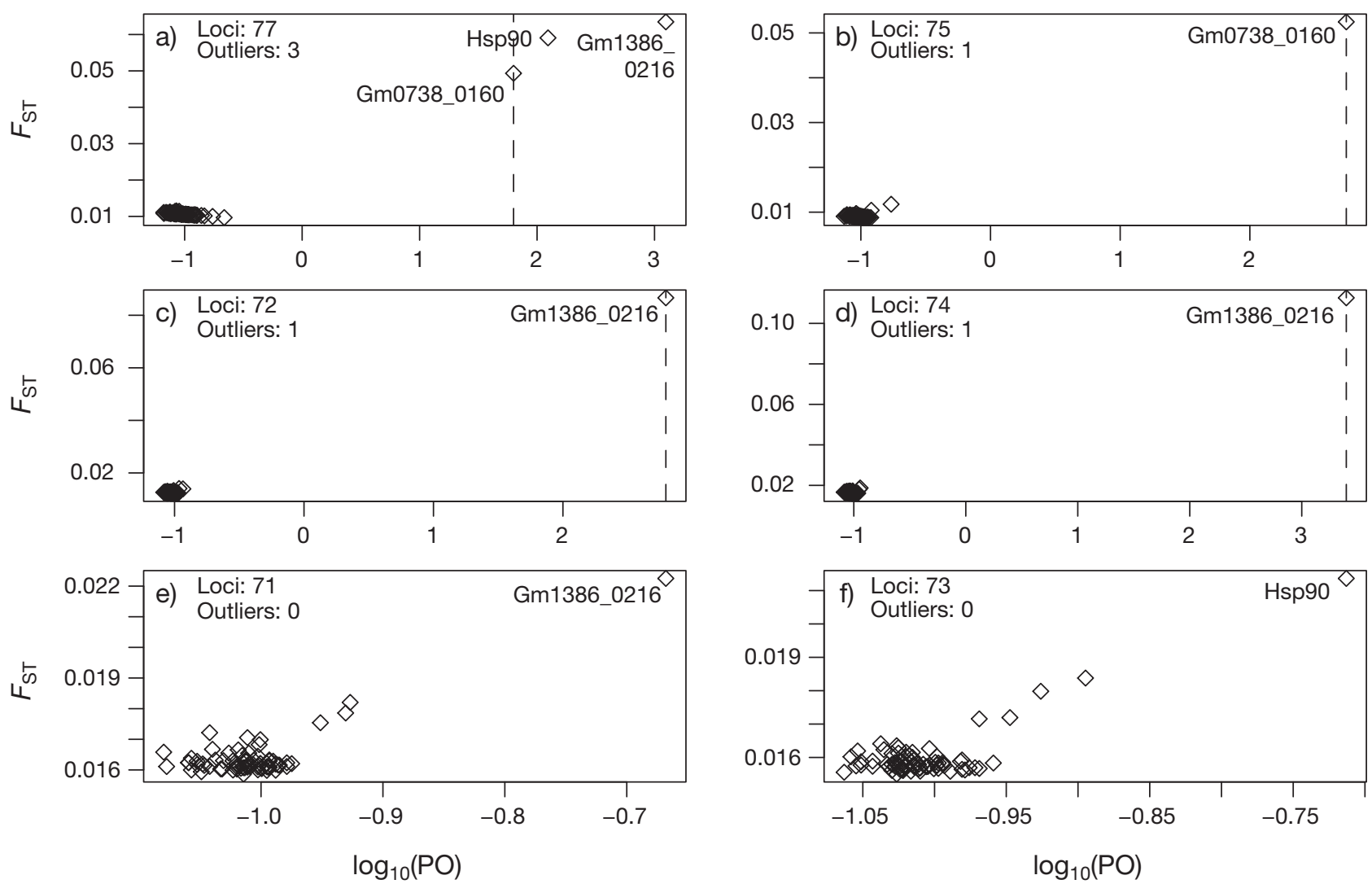

Fig. 3. Gadus morhua. Spatial scans for the identification of genetic differentiation $\left(F_{\mathrm{ST}}\right)$ outlier loci potentially subject to selection (a) 10 contemporary population samples from the North Sea and adjacent sea areas (KAT07, ENS07, SNS, ECH, CNS, NEN, NNS03, BLE03, FPL, FBA02); (b) 7 contemporary population samples from the North Sea (FPL, FBA02, KAT07 excluded); (c) 3 contemporary samples from the North Sea/Faroe Islands (NNS03, BLE03, FBA02); (d) 3 historical samples from the North Sea/Faroe Islands (NNS65, BLE65, FBA78); (e) 2 contemporary samples from the North Sea/Kattegat (ENS07, KAT07); (f) 2 historical samples from the North Sea/Kattegat (ENS99, KAT96). Vertical dashed lines mark $\log _{10}$ posterior odds (PO) of the threshold corresponding to a false discovery rate of $5 \%$. Loci with minor allele frequencies below $2 \%$ were removed in each simulation

\section{DISCUSSION}

We found strong evidence in our study that several gene-associated loci in Atlantic cod are under selection, or are linked to loci under selection, at local and microgeographical scales. Importantly, signals of selection were associated with different population samples, and only in some cases coincided with detectable neutral genetic population structure. These results have implications for our understanding of the distribution of adaptive genetic variation in marine fishes, and specifically for our understanding of population structure in North Sea cod, particularly in areas where neutral genetic markers reveal limited genetic structure or where such structure is absent.

\section{Long-term temporal stability of signals of adaptive evolution}

Results from analysis of neutral markers indicate long-term stability in neutral genetic structure in cod populations from the northern North Sea and around the Faroe Islands. These results confirm earlier microsatellite studies and suggest high effective-population sizes and thus low levels of genetic drift (Poulsen et al. 2006, Nielsen et al. 2007, Therkildsen et al. 2010).

In both historical and contemporary data sets from the northern North Sea, one particular locus (Gm1386_ 0216) exhibited a significantly elevated $F_{\mathrm{ST}}$. The allele frequency of this putative outlier locus is very distinct from that of Faroe Bank samples and shows marked divergence not only from North Sea cod but also from the Faroe Plateau sample. Gm1386_0216 is located in a protein homologous to vitellogenin, which is involved in the maturation of oocytes (Mañanós et al. 1997). Such differentiation could be associated with different spawning conditions or other life-history trait differences, although the nature of potential phenotypic effects of allelic variants of this gene remains speculative. While adaptive differences have been suggested previously for Faroe Bank and Faroe Plateau cod (e.g. in different fatty acid profiles of heart tissue; Joensen 
Table 3. Gadus morhua. Allele frequencies of significant outlier loci identified by BayeScan (Nielsen et al. 2009a)

\begin{tabular}{|lccccccccccccccc}
\hline Outliers & \multirow{2}{*}{ KAT96 } & KAT07 & ENS99 & ENS07 & ECH & SNS & CNS & \multirow{2}{*}{ NEN } & NNS65 NNS03 BLE65 & BLE03 & FBA78 & FBA02 & FPL \\
\hline Gm1386_0216 & 0.763 & 0.908 & 0.625 & 0.645 & 0.638 & 0.838 & 0.68 & 0.7 & 0.556 & 0.477 & 0.464 & 0.589 & 0.948 & 0.936 & 0.786 \\
Gm0738_0160 & 0.688 & 0.638 & 0.705 & 0.838 & 0.788 & 0.731 & 0.58 & 0.425 & 0.758 & 0.838 & 0.771 & 0.75 & 0.766 & 0.813 & 0.713 \\
Hsp90 & 0.788 & 0.821 & 0.974 & 0.91 & 0.974 & 0.85 & 0.99 & 0.962 & 1 & 0.975 & 1 & 1 & 1 & 1 & 1 \\
Gm0289_0495 & 0.225 & 0.2 & 0.206 & 0.238 & 0.211 & 0.313 & 0.17 & 0.167 & 0.156 & 0.113 & 0.08 & 0.154 & 0.172 & 0.113 & 0.145 \\
Gm0588_0274 & 0.925 & 0.949 & 0.926 & 0.913 & 0.875 & 0.938 & 0.92 & 0.949 & 0.922 & 0.913 & 0.972 & 0.897 & 0.887 & 0.913 & 0.875 \\
Gm1108_0332 & 0.663 & 0.675 & 0.65 & 0.615 & 0.581 & 0.7 & 0.65 & 0.692 & 0.742 & 0.738 & 0.583 & 0.59 & 0.707 & 0.625 & 0.5 \\
Gm1156_0573 & 0.388 & 0.55 & 0.338 & 0.488 & 0.45 & 0.438 & 0.39 & 0.397 & 0.355 & 0.275 & 0.313 & 0.413 & 0.406 & 0.25 & 0.325 \\
Rhod 1 & 0.038 & 0.013 & 0.068 & 0.025 & 0.025 & 0.013 & 0.05 & 0.077 & 0.063 & 0.026 & 0.026 & 0.05 & 0.078 & 0.063 & 0.075 \\
Aroma1_9 & 0.324 & 0.425 & 0.351 & 0.238 & 0.288 & 0.41 & 0.31 & 0.35 & 0.234 & 0.311 & 0.319 & 0.269 & 0.414 & 0.363 & 0.282 \\
Gm0627_0302 & 0.625 & 0.663 & 0.705 & 0.705 & 0.628 & 0.588 & 0.556 & 0.744 & 0.621 & 0.600 & 0.667 & 0.713 & 0.597 & 0.638 & 0.590 \\
\hline
\end{tabular}

et al. 2000), adaptive genetic markers distinguishing Faroe Bank and North Sea samples have so far not been identified. Gm1386_0216 could therefore be an important marker for identifying populations of origin, applicable to management and traceability of these weakly structured cod populations. Several studies have included the PanI locus as a key marker for demonstrating local adaptations in cod (e.g. Case et al. 2005, Pampoulie et al. 2006), where temperature, salinity and depth have been invoked as drivers of selection (Case et al. 2005). Nielsen et al. (2007) also revealed long-term temporal stability and nonsignificant changes in PanI allele frequencies over several decades in Faroe Bank and Faroe Plateau cod in the face of recent temperature increases in the southern part of the distribution range. This marker is, however, very close to fixation in both North Sea and Faroese populations, and therefore not useful for identifying population of origin of cod in these waters.

\section{Short-term temporal instability in an environmentally dynamic transition zone}

In the present study, neutral markers also revealed temporal stability in the eastern North Sea and Kattegat comparisons. Thus, temporal samples from Kattegat (KAT96 and KAT07) and the eastern North Sea (ENS99 and ENS07) had pairwise $F_{\mathrm{ST}}$ estimates of 0.0063 for Kattegat and 0.0003 for the eastern North Sea. Both values were non-significant, but the higher estimate for Kattegat could be due to more pronounced dynamic environmental conditions in the transition zone between the Baltic Sea and the North Sea than within the North Sea. Temporal instability was also evident when we focused specifically on the outlier loci identified when including all spatial samples. Thus, when analyzing samples from this area, Gm1386_0216 and Hsp90 were found to display elevated levels of population differentiation (although not statistically significant) in the contemporary and historical sam- ples, respectively. The lack of statistical significance in these tests could be due to reduced statistical power because of the low number of samples in these tests (Foll \& Gaggiotti 2008). We cannot exclude the possibility that these results are partly caused by sampling effects. However, they could also indicate a slight temporal movement of the identified hybrid zone for marine fish (Nielsen et al. 2003, 2005) in this environmentally dynamic sea area, with marked spatial gradients and inter-annual variation, particularly with respect to temperature and salinity conditions, thus potentially explaining the higher level of temporal differentiation in Kattegat samples. Alternatively, selection on cohorts in a dynamic environment could be operating, as suggested previously as an explanation for highly variable PanI allele frequencies between cohorts of Atlantic cod within a Norwegian fjord population (Karlsson \& Mork 2003).

\section{Signals of selection within the neutrally homogeneous North Sea}

Multidimensional scaling plots and pairwise $F_{\mathrm{ST}}$ estimates based on neutral markers suggest that neutral genetic differentiation within the North Sea is very limited, thus supporting earlier findings from this region (Hutchinson et al. 2001, Nielsen et al. 2009c). Consequently, spatial resolution in the North Sea of 82 putatively neutral SNPs does not seem to be higher than that of 8 to 10 microsatellite loci typically applied in earlier studies. This is not surprising, given that diallelic SNP markers are expected to be less informative than multi-allelic microsatellites (Kalinowski 2002), thus failing to detect low levels of genetic differentiation (see e.g. Ryynänen et al. 2007 for a thorough discussion).

Population structure in Atlantic cod within the northern North Sea has recently been thoroughly examined by Nielsen et al. (2009c), who found low and nonsignificant population structuring. However, when 
they included one microsatellite locus potentially under selection (Gmo132), population structure was found to be significant on microgeographical scales comparable to the geographical scales examined in this study. Thus, patterns of population structure were highly dependent on the inclusion of just one outlier locus. Results of the present study applying gene-associated markers support these conclusions, as only a few, presumably non-neutral, loci showed detectable levels of structuring within the North Sea.

Cod from the northeastern North Sea showed what appear to be signatures of adaptive divergence, mainly driven by Gm738_0160. In addition, we observed a lower frequency of the common allele in the central North Sea. Although caution must be exercised in making demographic inferences on the basis of genetic data (Lowe \& Allendorf 2010), such patterns of divergence across relatively small spatial scales indicate a level of population integrity commensurate with an enhanced potential for local adaptation. On a large scale, this allele, which is almost absent in northeast Arctic and Greenlandic samples (Nielsen et al. 2009a), also appears less frequently in northern Norwegian coastal cod, but at a higher frequency in southern Norwegian coastal cod (Moen et al. 2008), similar to the rest of the North Sea area. Earlier studies have shown that the cod population in the Viking area also seems to be isolated, as evidenced from many pairwise tests for genetic differentiation and an apparent grouping of short-term temporal Viking samples at the Gmo132 locus (Nielsen et al. 2009c), which has been shown to be subject to selection (Nielsen et al. 2006). While the specific function of the gene(s) linked to Gm738_0160 is unknown, results of the present and earlier studies suggest strongly that several loci may be involved in microgeographic adaptation in Atlantic cod within the North Sea region. Such inferences from genetic data are supported by variation in reproductive traits between cod populations from the southern and northern North Sea (Harrald et al. 2010). Using a common environment experiment on wild-caught juveniles raised to maturity, cod from the southern North Sea were found to mature at larger sizes than those from the northwestern North Sea, despite broadly similar growth rates (Harrald et al. 2010).

\section{Ecological or evolutionary populations?}

Among populations occupying sea areas exhibiting very low levels of neutral genetic population structure, adaptive markers can be valuable for studying imprints of fine-scaled differentiation, reflecting either fluctuating directional selection (Karlsson \& Mork 2003), ecological units not evident from neutral diver- gence (Nielsen et al. 2009c), or simply evolutionary units not yet at migration-drift equilibrium. In the current study, we addressed loci that previously had shown strong signatures of adaptive divergence on a larger geographic scale. Generally, it was evident from the outlier detection tests that there was strong agreement between micro- and macro-geographical patterns in terms of outlier loci identified (Moen et al. 2008, Nielsen et al. 2009a).

While independence under the evolutionary paradigm (i.e. evolutionary isolation and separation of evolutionary populations) requires significant reductions in gene flow (e.g. $N_{\mathrm{e}} \times m<25$ under the island model), independence under the ecological paradigm (i.e. demographic/ecological isolation and separation of ecological populations) may still be possible with considerable levels of migration (e.g. $m<0.1$ ) (Waples \& Gaggiotti 2006). Here we failed to detect population structure within the North Sea using putative neutral markers, and our results might therefore reflect microgeographical separation of demographically (but not evolutionarily) independent units. However, we cannot exclude the possibility that the signal of elevated structure for locus Gm738_0160 reflects a recently emerged strong reproductive separation of evolutionary units, not yet at migration-drift equilibrium. In such cases, markers under selection might be expected to differentiate populations at higher rates than neutral genetic markers (Nei 1987). Local ecological populations are often of particular interest for fisheries and conservation management (Waples et al. 2008). In Atlantic cod, strong demographic changes have occurred due to fishing (see Hutchings \& Fraser 2008), and migration rates among natural populations could thus recently have been reduced. If this scenario holds, current signatures of adaptive differentiation might be followed by stronger demographic independence in the future. Thus, 'genetic monitoring' (Schwartz et al. 2007) of loci subject to selection can yield useful information on dynamic processes at microgeographical scales, and potentially separate groups of fish sampled along ecological dimensions in populations showing geographical patterns of differentiation similar to those described here.

In contrast to results obtained when analyzing samples from the North Sea, we found evidence for significant spatial neutral genetic structure when analyzing long-term spatio-temporal samples on a slightly larger geographical scale. Much of the population structure was associated with the Faroese samples and appeared to be temporally stable. Our results therefore support earlier studies indicating isolation of Faroe Islands cod (Pampoulie et al. 2008a,b). Consequently, our finding of highly significant and temporally stable patterns of adaptive divergence driven by the Faroe 
Bank sample may well indicate the presence of an evolutionarily separate population. While the lack of an historical sample from the Faroe Plateau prevents detailed analysis of a possible separation of cod from the Faroe Bank and the Faroe Plateau, a marginally significant neutral difference between contemporary samples (Table A1), temporally similar allele frequencies at the Faroe Bank and marked allele frequency differences between Faroe Bank and Faroe Plateau samples for the outlier locus (Gm1386_0216; Table 3) all suggest the presence of separate populations on the Faroe Bank and the Faroe Plateau (see also Nielsen et al. 2009c).

The samples analyzed from the transition zone between the Baltic and North Seas do not indicate completely evolutionarily stable populations, but may reflect short-term temporal dynamics in a transition zone between 2 evolutionarily stable populations (Nielsen et al. 2001, 2003). Several studies have identified significant levels of population structure at microgeographical scales in Atlantic cod when applying a limited set of presumed neutral genetic markers (Hutchinson et al. 2001, Knutsen et al. 2003, Jorde et al. 2007). While results from the present study should not be used to refute earlier findings, they do illustrate the importance of evaluating variation among markers, since one or few loci under selection could influence conclusions significantly (see also discussion in Nielsen et al. 2009c).

\section{CONCLUSIONS}

In general, we consistently identified the same loci as significant $F_{\mathrm{ST}}$ outliers, suggesting that these loci are under positive selection or linked to loci under selection. While such signatures of selection can be the result of a heterogeneous environment that favors different alleles, several neutral evolutionary processes could also have affected these results (Charlesworth et al. 2003). For instance, Vasemägi (2006) showed that a variable number of neutral loci could display clinal patterns under a model of neutral isolation by distance. In the present study, however, outlier loci did generally not vary clinally with either latitude or longitude. Thus, the results indicate that outlier signals are associated with one or perhaps a few population samples, supporting a strong role for local selection over neutral isolation by distance. However, even if selection is implied, it can be very difficult to separate effects of past selection from ongoing selection in local populations (Pogson 2001, Bierne 2010). For instance, global hitchhiking of a neutral allele with a favorable allele in a structured population may result in increased $F_{\mathrm{ST}}$ between the population of origin and neighboring pop- ulations (Bierne 2010). This signal is broken down only slowly by gene flow and recombination (Bierne 2010). Chromosome walking can be used to separate signals arising from local and global hitchhiking scenarios (Bierne 2010), but this is not possible with the data currently available for Atlantic cod. Thus, in principle, the signals of adaptive evolution described in this study could reflect the early phases of a global hitchhiking scenario, thus reflecting not current but past selection. However, the fact that outliers identified in the present study have previously been identified as outliers in different populations at larger geographical scales (Moen et al. 2008, Nielsen et al. 2009a) lends some support to the hypothesis of ongoing selection, since it appears unlikely that the same mutation should be at the same early stage of global hitchhiking in several populations throughout the distribution of the species. Thus, although it is difficult to rule out alternative explanations, we find that our results are most compatible with a hypothesis of local adaptive evolution.

In conclusion, through analysis at both temporal and spatial scales, we have found that apparent signals of local adaptive divergence can be found under both restricted gene flow (e.g. Faroe Bank) and high geneflow (North Sea) scenarios in Atlantic cod at local geographical scales. Understanding the geographical scale and temporal stability of adaptive divergence is important for the development of predictive models of shifts in population and species distributions in response to changing environments. Management considerations should therefore also take into account local population structure under the ecological paradigm, since such locally distributed intra-specific genetic variation could underpin resilience and persistence (Hoffmann \& Willi 2008). Of particular importance would be the integration of genomic variation and additive genetic trait variance (Kawecki \& Ebert 2004, Jensen et al. 2008), and ultimately fitness variation in the wild (Wiehe et al. 2007, Andersen et al. 2008, Mäkinen et al. 2008, Stinchcombe \& Hoekstra 2008). Rapid developments in cod genomics, such as full genome sequencing and linkage map construction (Johansen et al. 2009, Moen et al. 2009, Hubert et al. 2010), greatly enhance the potential for pursuing such approaches in cod and related non-model species.

Acknowledgements. We thank T. Moen and P. Berg for assistance with SNP genotyping; D. Meldrup, J. Frydenberg and C. Håkansson for technical assistance; E. Magnussen, J. E. Beyer and N. Gerner Andersen for providing cod samples; R. Ogden for providing DNA sequence variation; and M. Foll for assistance with BayeScan. Several cod samples included in this study were collected as a part of the EU-funded project METACOD (grant no. Q5RS-2001-00953) and the project REX II financed by the The Danish Ministry of Food, Agriculture and Fisheries and the European Fisheries Fund. N.A.P. 
acknowledges funding by the International School of Biodiversity Sciences (ISOBIS). This work was financially supported by the European Network of Excellence 'Marine Genomics Europe' (grant no. GOCE-CT-2004-505403) and the EU projects 'FinE' (grant no: 044276) and FishPopTrace (FP7-2007-2013; grant agreement number KBBE 212399).

\section{LITERATURE CITED}

Andersen $\varnothing$, Wetten $\mathrm{OF}, \mathrm{De}$ Rosa $\mathrm{MC}$, André $\mathrm{C}$ and others (2009) Haemoglobin polymorphisms affect the oxygenbinding properties in Atlantic cod populations. Proc R Soc B 276:833-841

Barton NH (2000) Genetic hitchhiking. Philos Trans R Soc Lond B 355:1553-1562

Beaumont MA, Balding DJ (2004) Identifying adaptive genetic divergence among populations from genome scans. Mol Ecol 13:969-980

Bentzen P, Taggart CT, Ruzzante DE, Cook D (1996) Microsatellite polymorphism and the population structure of Atlantic cod (Gadus morhua) in the northwest Atlantic. Can J Fish Aquat Sci 53:2706-2721

Bierne N (2010) The distinctive footprints of local hitchhiking in a varied environment and global hitchhiking in a subdivided population. Evolution 64:3254-3272

Bradbury IR, Hubert S, Higgins B, Borza T and others (2010) Parallel adaptive evolution of Atlantic cod on both sides of the Atlantic Ocean in response to temperature. Proc Biol Sci 277:3725-3734

Brander K (ed) (2005) Spawning and life history information for North Atlantic cod stocks. Cooporative Research Report No. 274. International Council for the Exploration of the Sea, Copenhagen

Case RAJ, Hutchinson WF, Hauser L, Van Oosterhout C, Carvalho GR (2005) Macro- and micro-geographic variation in pantophysin (PanI) allele frequencies in NE Atlantic cod Gadus morhua. Mar Ecol Prog Ser 301:267-278

> Charlesworth B, Charlesworth D, Barton NH (2003) The effects of genetic and geographic structure on neutral variation. Annu Rev Ecol Syst 34:99-125

Conover DO, Clarke LM, Munch SB, Wagner N (2006) Spatial and temporal scales of adaptive divergence in marine fishes and the implications for conservation. J Fish Biol 69:21-47

Estoup A, Largiader CR, Perrot E, Chourrout D (1996) Rapid one-tube DNA extraction for reliable PCR detection of fish polymorphic markers and transgenes. Mol Mar Biol Biotechnol 5:295-298

Excoffier L, Laval G, Schneider S (2005) Arlequin version 3.0: an integrated software package for population genetics data analysis. Evol Bioinform Online 1:47-50

Foll M, Gaggiotti O (2008) A genome-scan method to identify selected loci appropriate for both dominant and codominant markers: a Bayesian perspective. Genetics 180: 977-993

> Garvin MR, Saitoh K, Gharrett AJ (2010) Application of single nucleotide polymorphisms to non-model species: a technical review. Mol Ecol Resour 10:915-934

Goudet J (1995) FSTAT (version 1.2): a computer program to calculate F-statistics. J Hered 86:485-486

> Grabowski TB, Young SP, Libungan LA, Steinarsson A, Marteinsdóttir G (2009) Evidence of phenotypic plasticity and local adaption in metabolic rates between components of the Icelandic cod (Gadus morhua L.) stock. Environ Biol Fishes 86:361-370

Harrald M, Wright PJ, Neat FC (2010) Substock variation in reproductive traits in North Sea cod (Gadus morhua). Can J Fish Aquat Sci 67:866-876

Hemmer-Hansen J, Nielsen EE, Frydenberg J, Loeschcke V (2007) Adaptive divergence in a high gene flow environment: Hsc70 variation in the European flounder (Platichthys flesus L.). Heredity 99:592-600

> Hendry AP, Day T, Taylor EB (2001) Population mixing and the adaptive divergence of quantitative traits in discrete populations: a theoretical framework for empirical tests. Evolution 55:459-466

> Hoffmann AA, Willi Y (2008) Detecting genetic responses to environmental change. Nat Rev Genet 9:421-432

Hubert S, Higgins B, Borza T, Bowman S (2010) Development of a SNP resource and a genetic linkage map for Atlantic cod (Gadus morhua). BMC Genomics 11:191

- Hutchings JA, Fraser DJ (2008) The nature of fisheries- and farming-induced evolution. Mol Ecol 17:294-313

> Hutchings JA, Swain DP, Rowe S, Eddington JD, Puvanendran V, Brown JA (2007) Genetic variation in life-history reaction norms in a marine fish. Proc Biol Sci 274: 1693-1699

> Hutchinson WF, Carvalho GR, Rogers SI (2001) Marked genetic structuring in localised spawning populations of cod Gadus morhua in the North Sea and adjoining waters, as revealed by microsatellites. Mar Ecol Prog Ser 223: 251-260

Jensen LF, Hansen MM, Pertoldi C, Holdensgaard G, Mensberg KLD, Loeschcke V (2008) Local adaptation in brown trout early life-history traits: implications for climate change adaptability. Proc Biol Sci 275:2859-2868

Joensen H, Steingrund P, Fjallstein I, Grahl-Nielsen O (2000) Discrimination between two reared stocks of cod (Gadus morhua) from the Faroe Islands by chemometry of the fatty acid composition in the heart tissue. Mar Biol 136: $573-580$

Johansen SD, Coucheron DH, Andreassen M, Karlsen BO and others (2009) Large-scale sequence analyses of Atlantic cod. New Biotechnol 25:263-271

> Jorde PE, Knutsen H, Espeland SH, Stenseth NC (2007) Spatial scale of genetic structuring in coastal cod Gadus morhua and geographic extent of local populations. Mar Ecol Prog Ser 343:229-237

Jørgensen C, Enberg K, Dunlop ES, Arlinghaus R and others (2007) Ecology: managing evolving fish stocks. Science 318:1247-1248

Kalinowski ST (2002) How many alleles per locus should be used to estimate genetic distances? Heredity 88:62-65

Karlsson S, Mork J (2003) Selection-induced variation at the pantophysin locus (PanI) in a Norwegian fjord population of cod (Gadus morhua L.). Mol Ecol 12:3265-3274

Kawecki TJ, Ebert D (2004) Conceptual issues in local adaptation. Ecol Lett 7:1225-1241

Knutsen H, Jorde PE, Andre C, Stenseth C (2003) Fine-scaled geographical population structuring in a highly mobile marine species: the Atlantic cod. Mol Ecol 12:385-394

> Larsen PF, Nielsen EE, Williams TD, Hemmer-Hansen J and others (2007) Adaptive differences in gene expression in European flounder (Platichthys flesus). Mol Ecol 16: 4674-4683

Lenormand T (2002) Gene flow and the limits to natural selection. Trends Ecol Evol 17:183-189

Lewontin RC, Krakauer J (1973) Distribution of gene frequency as a test of the theory of the selective neutrality of polymorphisms. Genetics 74:175-195

Lowe WH, Allendorf FW (2010) What can genetics tell us about population connectivity? Mol Ecol 19:3038-3051

Luikart G, England PR, Tallmon D, Jordan S, Taberlet P 
(2003) The power and promise of population genomics: from genotyping to genome typing. Nat Rev Genet 4: 981-994

Mäkinen HS, Cano JM, Merilä J (2008) Identifying footprints of directional and balancing selection in marine and freshwater three-spined stickleback (Gasterosteus aculeatus) populations. Mol Ecol 17:3565-3582

Mañanós EL, Rodríguez JN, Menn FL, Zanuy S, Carrillo M (1997) Identification of vitellogenin receptors in the ovary of a teleost fish, the Mediterranean sea bass (Dicentrarchus labrax). Reprod Nutr Dev 37:51-61

Marcil J, Swain DP, Hutchings JA (2006) Genetic and environmental components of phenotypic variation in body shape among populations of Atlantic cod (Gadus morhua L.). Biol J Linn Soc 88:351-365

Moen T, Hayes B, Nilsen F, Delghandi M and others (2008) Identification and characterisation of novel SNP markers in Atlantic cod: evidence for directional selection. BMC Genet 9:18

Moen T, Delghandi M, Wesmajervi MS, Westgaard JI, Fjalestad KT (2009) A SNP/microsatellite genetic linkage map of the Atlantic cod (Gadus morhua). Anim Genet 40:993-996

Nei M (1987) Molecular evolutionary genetics. Columbia University Press, New York, NY

Nielsen EE, Hansen MM, Schmidt C, Meldrup D, Grønkjær P (2001) Fisheries: population of origin of Atlantic cod. Nature 413:272

Nielsen EE, Hansen MM, Ruzzante DE, Meldrup D, Grønkjær P (2003) Evidence of a hybrid-zone in Atlantic cod (Gadus morhua) in the Baltic and the Danish Belt Sea revealed by individual admixture analysis. Mol Ecol 12:1497-1508

- Nielsen EE, Grønkjær P, Meldrup D, Paulsen H (2005) Retention of juveniles within a hybrid zone between North Sea and Baltic Sea Atlantic cod (Gadus morhua). Can J Fish Aquat Sci 62:2219-2225

Nielsen EE, Hansen MM, Meldrup D (2006) Evidence of microsatellite hitch-hiking selection in Atlantic cod (Gadus morhua L.): implications for inferring population structure in nonmodel organisms. Mol Ecol 15:3219-3229

Nielsen EE, MacKenzie BR, Magnussen E, Meldrup D (2007) Historical analysis of Pan I in Atlantic cod (Gadus morhua): temporal stability of allele frequencies in the southeastern part of the species distribution. Can J Fish Aquat Sci 64:1448-1455

> Nielsen EE, Hemmer-Hansen J, Poulsen NA, Loeschcke V and others (2009a) Genomic signatures of local directional selection in a high gene flow marine organism; the Atlantic cod (Gadus morhua). BMC Evol Biol 9:276

> Nielsen EE, Hemmer-Hansen J, Larsen PF, Bekkevold D (2009b) Population genomics of marine fishes: identifying adaptive variation in space and time. Mol Ecol 18: 3128-3150

> Nielsen EE, Wright P, Wright PJ, Hemmer-Hansen J, Poulsen NA, Gibb IM, Meldrup D (2009c) Microgeographical population structure of cod Gadus morhua in the North Sea and west of Scotland: the role of sampling loci and individuals. Mar Ecol Prog Ser 376:213-225

O'Leary DB, Coughlan J, Dillane E, McCarthy TV, Cross TF (2007) Microsatellite variation in cod Gadus morhua throughout its geographic range. J Fish Biol 70:310-335

> Olsen EM, Knutsen H, Gjøsæter J, Jorde PE, Knutsen JA, Stenseth NC (2008) Small-scale biocomplexity in coastal Atlantic cod supporting a Darwinian perspective on fisheries management. Evol Appl 1:524-533

Pampoulie C, Ruzzante DE, Chosson V, Jörundsdóttir TD and others (2006) The genetic structure of Atlantic cod (Gadus morhua) around Iceland: insight from microsatellites, the Pan I locus, and tagging experiments. Can J Fish Aquat Sci 63:2660-2674

Pampoulie C, Stefansson MO, Jorundsdóttir TD, Danilowicz BS, Danielsdóttir AK (2008a) Recolonization history and large-scale dispersal in the open sea: the case study of the North Atlantic cod, Gadus morhua L. Biol J Linn Soc 94: 315-329

Pampoulie C, Steingrund P, Stefánsson MÖ, Danielsdóttir AK (2008b) Genetic divergence among East Icelandic and Faroese populations of Atlantic cod provides evidence for historical imprints at neutral and non-neutral markers. ICES J Mar Sci 65:65-71

> Pogson GH (2001) Nucleotide polymorphism and natural selection at the pantophysin (Pan I) locus in the Atlantic cod, Gadus morhua (L.). Genetics 157:317-330

Poulsen NA, Nielsen EE, Schierup MH, Loeschcke V, Grønkjær P (2006) Long-term stability and effective population size in North Sea and Baltic Sea cod (Gadus morhua). Mol Ecol 15:321-331

R Development Core Team (2010) R: a language and environment for statistical computing. R Foundation for Statistical Computing, Vienna

Rice WR (1989) Analyzing tables of statistical tests. Evolution 43:223-225

Ruzzante DE, Taggart CT, Cook D, Goddard SV (1996) Genetic differentiation between inshore and offshore Atlantic cod (Gadus morhua) off Newfoundland: microsatellite DNA variation and antifreeze level. Can J Fish Aquat Sci 53:634-645

Ryynänen HJ, Tonteri A, Vasemägi A, Primmer CR (2007) A comparison of biallelic markers and microsatellites for the estimation of population and conservation genetic parameters in Atlantic salmon (Salmo salar). J Hered 98: 692-704

> Schulte PM (2001) Environmental adaptations as windows on molecular evolution. Comp Biochem Physiol B 128: $597-611$

Schwartz MK, Luikart G, Waples RS (2007) Genetic monitoring as a promising tool for conservation and management. Trends Ecol Evol 22:25-33

Slatkin M (1973) Gene flow and selection in a cline. Genetics 75:733-756

Slatkin M (1987) Gene flow and the geographic structure of natural populations. Science 236:787-792

Smith BJ (2007) boa: an R package for MCMC output convergence assessment and posterior inference. J Stat Softw 21:1-37

Smith JM, Haigh J (1974) The hitch-hiking effect of a favourable gene. Genet Res 23:23-35

Stinchcombe JR, Hoekstra HE (2008) Combining population genomics and quantitative genetics: finding the genes underlying ecologically important traits. Heredity 100: $158-170$

Storz JF (2005) Using genome scans of DNA polymorphism to infer adaptive population divergence. Mol Ecol 14: $671-688$

Therkildsen NO, Nielsen EE, Swain DP, Pedersen JS (2010) Large effective population size and temporal genetic stability in Atlantic cod (Gadus morhua) in the southern Gulf of St. Lawrence. Can J Fish Aquat Sci 67:1585-1595

Thomson RC, Wang IJ, Johnson JR (2010) Genome-enabled development of DNA markers for ecology, evolution and conservation. Mol Ecol 19:2184-2195

- Vasemägi A (2006) The adaptive hypothesis of clinal variation revisited: single-locus clines as a result of spatially restricted gene flow. Genetics 173:2411-2414 
Waples RS (1998) Separating the wheat from the chaff: patterns of genetic differentiation in high gene flow species. J Hered 89:438-450

> Waples RS, Gaggiotti O (2006) What is a population? An empirical evaluation of some genetic methods for identifying the number of gene pools and their degree of connectivity. Mol Ecol 15:1419-1439

Waples RS, Punt AE, Cope JM (2008) Integrating genetic data into management of marine resources: How can we do it better? Fish Fish 9:423-449

- Ward RD, Woodwark M, Skibinski DOF (1994) A comparison of genetic diversity levels in marine, freshwater, and anadromous fishes. J Fish Biol 44:213-232

> Weir BS, Cockerham CC (1984) Estimating F-statistics for the analysis of population structure. Evolution 38:1358-1370

Wiehe T, Nolte V, Zivkovic D, Schlötterer C (2007) Identification of selective sweeps using a dynamically adjusted number of linked microsatellites. Genetics 175:207-218

Young FW (1996) ViSta: the visual statistics system, Research Memo 94-1(b), 2nd edn. L. L. Thurstone Psychometric Laboratory, University of North Carolina, Chapel Hill, NC 


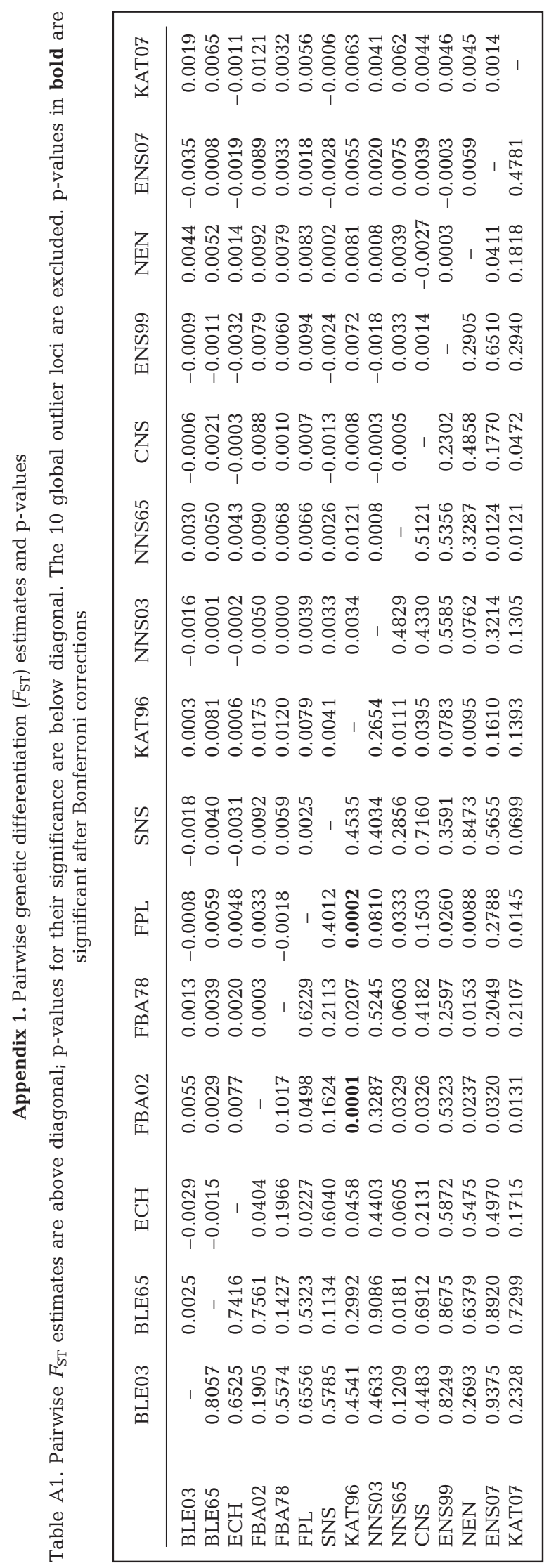

Editorial responsibility: Philippe Borsa,

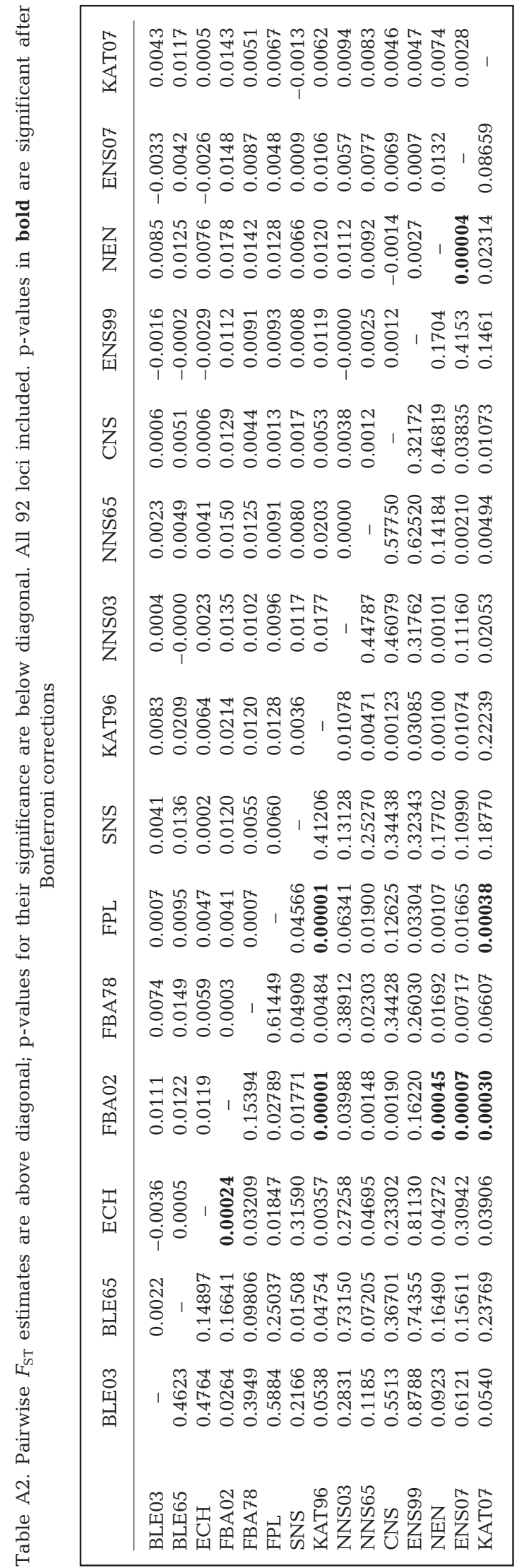

Submitted: September 9, 2010; Accepted: June 7, 2011

Proofs received from author(s): August 24, 2011 